\title{
Rate of non-linearity in DMS aerosol-cloud-climate interactions
}

\author{
M. A. Thomas ${ }^{1,3}$, P. Suntharalingam ${ }^{1}$, L. Pozzoli ${ }^{2, *}$, A. Devasthale ${ }^{3}$, S. Kloster ${ }^{4,5}$, S. Rast ${ }^{5}$, J. Feichter ${ }^{5}$, and \\ T. M. Lenton ${ }^{1,6}$ \\ ${ }^{1}$ School of Environmental Sciences, University of East Anglia, Norwich, UK \\ ${ }^{2}$ European Commission, Joint Research Centre, Institute for Environment and Sustainability, Ispra, Italy \\ ${ }^{3}$ Swedish Meteorological and Hydrological Institute, Norrkoping, Sweden \\ ${ }^{4}$ Earth and Atmospheric Sciences, Cornell University, Ithaca, NY, USA \\ ${ }^{5}$ Department of Atmospheric Sciences, Max-Planck-Institute for Meteorology, Hamburg, Germany \\ ${ }^{6}$ Department of Geography, University of Exeter, Exeter, Devon, UK \\ *now at: Eurasia Institute of Earth Sciences, Istanbul Technical University, Istanbul, Turkey
}

Received: 20 January 2011 - Published in Atmos. Chem. Phys. Discuss.: 18 May 2011

Revised: 12 September 2011 - Accepted: 3 November 2011 - Published: 10 November 2011

\begin{abstract}
The degree of non-linearity in DMS-cloudclimate interactions is assessed using the ECHAM5HAMMOZ model by taking into account end-to-end aerosol chemistry-cloud microphysics link. The evaluation is made over the Southern oceans in austral summer, a region of minimal anthropogenic influence. In this study, we compare the DMS-derived changes in the aerosol and cloud microphysical properties between a baseline simulation with the ocean DMS emissions from a prescribed climatology, and a scenario where the DMS emissions are doubled. Our results show that doubling the DMS emissions in the current climate results in a non-linear response in atmospheric DMS burden and subsequently, in $\mathrm{SO}_{2}$ and $\mathrm{H}_{2} \mathrm{SO}_{4}$ burdens due to inadequate $\mathrm{OH}$ oxidation. The aerosol optical depth increases by only $\sim 20 \%$ in the $30^{\circ} \mathrm{S}-75^{\circ} \mathrm{S}$ belt in the SH summer months. This increases the vertically integrated cloud droplet number concentrations (CDNC) by $25 \%$. Since the vertically integrated liquid water vapor is constant in our model simulations, an increase in CDNC leads to a reduction in cloud droplet radius of $3.4 \%$ over the Southern oceans in summer. The equivalent increase in cloud liquid water path is $10.7 \%$. The above changes in cloud microphysical properties result in a change in global annual mean radiative forcing at the TOA of $-1.4 \mathrm{~W} \mathrm{~m}^{-2}$. The results suggest that the DMS-cloud microphysics link is highly non-linear. This has implications for future studies investigating the DMS-cloud climate feedbacks in a warming world and for studies evaluating geoengineering options to counteract warming by modulating low level marine clouds.
\end{abstract}

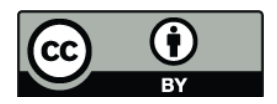

Correspondence to: $\mathrm{M}$. A. Thomas (manu.thomas@smhi.se)

\section{Introduction}

Aerosols can influence the radiative balance of the Earth both directly and indirectly. They can absorb and scatter the incoming solar and outgoing infrared radiation and impart a direct radiative forcing to the climate system. Aerosols can also act as cloud condensation nuclei, alter the microphysical properties of clouds and impose an indirect radiative forcing to the climate system (Carslaw et al. (2010); Lohmann and Feichter (2005) and references therein). The first indirect aerosol effect concerns the change in cloud albedo due to an increase in cloud condensation nuclei $(\mathrm{CCN})$ concentration. The increased CCN load leads to an increased number of smaller cloud droplets under constant liquid water content (Twomey, 1974, 1977). Smaller cloud droplets reduce the coalescence efficiency resulting in an increase in the lifetime of clouds, which results in the second indirect aerosol effect, also known as the cloud lifetime effect (Albrecht, 1989).

Aerosol indirect effects are considered to be among the largest source of uncertainties in radiative forcing estimates derived from global chemistry-climate models (Solomon et al., 2007). Reviews of model estimates of indirect aerosol effects (IAE) are given in Lohmann and Feichter (2005); Quaas et al. (2009); Carslaw et al. (2010). These studies indicate that both the first and second indirect aerosol effects tend to cool the Earth-atmosphere system, with TOA (top of the atmosphere) radiative forcing estimates ranging from -0.5 to $-1.9 \mathrm{~W} \mathrm{~m}^{-2}$ for the first indirect aerosol effect and from -0.3 to $-1.4 \mathrm{~W} \mathrm{~m}^{-2}$ for the second indirect aerosol effect. This range in the TOA radiative forcing results from model specific variations in the representation of aerosol species, aerosol microphysics and aerosol-cloud interactions. When

Published by Copernicus Publications on behalf of the European Geosciences Union. 
these models are constrained by satellite data, the forcing is estimated as $-0.7 \pm 0.4 \mathrm{~W} \mathrm{~m}^{-2}$ (Quaas et al., 2009).

Modulating cloud microphysical properties via first and second order indirect aerosol effects by the introduction of additional aerosols that can act as cloud condensation nuclei is one of the many methodologies suggested to counteract warming. It is proposed that this can be done either by artificially and mechanically spraying sea salt aerosols in the atmosphere or by stimulating DMS aerosol-cloud feedback by iron fertilization (for example, the recent studies by Boyd (2008); Jones et al. (2009); Korhonen et al. (2010); Wingenter et al. (2007); Woodhouse et al. (2008)). However, these studies focus only a particular part of the DMS aerosol-cloud-climate feedback loop often ignoring the underlying non-linearities in aerosol-cloud interactions. Our study would provide estimates of the degree of non-linearity expected in aerosol-cloud interactions in order to evaluate indirect aerosol radiative forcing more accurately.

Some earlier studies have noted potential non-linearity in aerosol-CDNC formation pathways. For example, Pandis et al. (1994) and Russell et al. (1994) show that under low DMS emissions, the DMS-CCN link is non-linear due to heterogeneous reactions on sea salt; the link is likely to be linear in pristine marine conditions when DMS fluxes are higher $\left(>2.5 \mu \mathrm{mol} \mathrm{m}{ }^{-2} \mathrm{~d}^{-1}\right)$. More recently, in the context of geoengineering, Woodhouse et al. (2008) have demonstrated that the conversion of DMS to aerosol and CCN does not scale linearly and can not be represented by a simple production efficiency. By increasing the DMS sea water concentrations five fold, a $1.4 \%$ increase in $\mathrm{CCN}$ was simulated over the Southern oceans, compared to a $10 \%$ increase estimated by Wingenter et al. (2007). Using a fully coupled atmosphereocean climate model, Jones et al. (2009) and Rasch et al. (2009) examined the impact of directly increasing CDNC in the low level marine stratocumulus cloud regions by setting the CDNC in the models to $375 \mathrm{~cm}^{-3}$ and $1000 \mathrm{~cm}^{-3}$ respectively, thereby suggesting methods that may help to override the effects of global warming, though the response was not uniform globally. Instead of imposing an increase of CDNC, Korhonen et al. (2010) used a global aerosol transport model to quantify the change in droplet number concentrations resulting from an increase in sea salt emissions as prescribed by Salter et al. (2008); they showed that the pathway from the emissions to CDNC formation was non linear because of the dilution and removal of particles from the atmosphere, and also because the injection of a large number of accumulation mode particles suppressed cloud supersaturation. The regional median CDNC in their study in the seeded regions range from $246-314 \mathrm{~cm}^{-3}$ which is much lower than the CDNC values assumed by Latham et al. (2008) and Jones et al. (2009).

While deriving motivation from the above results, the present study extends them by using a global aerosolchemistry-cloud microphysics-climate model (ECHAM5HAMMOZ) that accounts directly for the process based link- ages between DMS emissions, aerosol formation, and cloud microphysics. We will evaluate the degree of non-linearity in the downstream formation of sulphate, in aerosol optical depth (AOD), in cloud microphysical properties such as CDNC, CD effective radii, liquid water path, and in TOA radiative forcing.

\section{Model, experimental set up and methodology}

Details of the configuration of our DMS-sulfate aerosol simulations using ECHAM5-HAMMOZ were presented in Thomas et al. (2010). The performance of the different model components of ECHAM5-HAMMOZ model was evaluated in several studies. The aerosol module, ECHAM5HAM was evaluated extensively by Stier et al. (2005) and the chemistry component, ECHAM5-MOZ by Auvray et al. (2007), Rast et al. (2011) and Pozzoli (2007). The modeled aerosol optical depth in Southern Hemisphere was in good agreement when compared with satellite observations (Stier et al., 2005; Pozzoli et al., 2008b). The size distribution, number concentration and optical properties are reproduced well by the coupled model, though the agreement is better near the surface than in the upper troposphere. The annual mean burdens of the aerosol species simulated by ECHAM5HAMMOZ was more or less similar compared to those simulated by ECHAM5-HAMMOZ model (Pozzoli et al., 2008b). Regional improvements in the sulfate composition over $\mathrm{Eu}-$ rope and US was noted with ECHAM5-HAMMOZ, primarily, due to the interactive calculation of $\mathrm{OH}$ concentrations in ECHAM5-HAMMOZ compared to the climatological values used in ECHAM5-HAM. Aerosol-cloud interactions are parameterized using the cloud microphysics scheme described in Lohmann et al. (2007). A prognostic equation is used to describe the relationship between aerosol number concentration and cloud droplet nucleation. This equation accounts for the microphysical processes such as nucleation, autoconversion, self-collection, accretion by rain and snow, freezing and evaporation of cloud droplets. The autoconversion rate of cloud droplets to form raindrops is important for the cloud lifetime effect and is parameterized based on cloud liquid water mass mixing ratio and the cloud droplet number concentration (Khairoutdinov and Kogan, 2000). The nucleation rate of cloud droplets is based on the total number of aerosols, the updraft velocity and a factor, which takes the aerosol composition and size spectrum into account (Chuang and Penner, 1995). The cloud fraction is predicted based on the parameterization scheme by Tompkins (2002). The effective radius for cloud droplets is obtained from the mean volume radius and a simple parameterization of the dispersion effect that depends on the cloud droplet number concentration (Peng and Lohmann, 2003). Lohmann et al. (1999, 2007) evaluated the cloud microphysical variables and a realistic agreement was found between modeled and observed mean liquid water path, $\mathrm{CDNC}$ and effective radius. 
In Thomas et al. (2010), the relevant parameters such as the DMS flux to the atmosphere, sulfate distribution and cloud microphysical variables were evaluated. The simulated global annual DMS flux to the atmosphere was estimated to be $23.3 \mathrm{Tg}(\mathrm{S}) \mathrm{yr}^{-1}$ and agrees well with the estimates of Boucher et al. (2003) that used the same gas exchange parameterization of Nightingale et al. (2000) and Kettle and Andreae (2000) DMS climatology. The seasonal variation in modeled nssSO4 ${ }^{2-}$ in our baseline simulation (CTRL) over the southern oceans is comparable to those of Gondwe et al. (2003) who estimated a 7-8 times increase in summer DMS emissions compared to winter. The simulated CD effective radii and cloud liquid water path agree closely with satellite data, but, the model seems to overestimate the CDNC over the $30^{\circ} \mathrm{S}-60^{\circ} \mathrm{S}$ latitude belt in summer.

Simulations are performed with T42L31 $\left(\sim 2.8 \times 2.8^{\circ}\right.$ and 31 levels from surface to $10 \mathrm{hPa}$ ) resolution by nudging the model with the ECMWF ERA-40 meteorological fields for the year 1999/2000. In Thomas et al. (2010), two simulations were carried out: [1] "CTRL" simulation for which the ocean DMS sea water concentrations were prescribed from the Kettle and Andreae (2000) climatology and [2] a "wo_ODMS" simulation with no ocean DMS emissions. In the present study, we perform, in addition, a 12-month simulation (December 1999-November 2000) in which the ocean DMS sea water concentrations is doubled (referred to as "2X_ODMS", hereafter in the text). Other emissions include anthropogenic and wildfire $\mathrm{SO}_{2}$, black carbon and organic carbon form the background aerosol concentrations, and are held fixed in our simulations in addition to the interactively computed sea salt and dust emissions. Over the Southern oceans, in addition to DMS emissions, the dominant aerosol species are wind generated sea spray particles which in the model, is parameterized following Monahan et al. (1986) scheme (for particles in the range 0.1 to $10 \mu \mathrm{m}$ ) and Smith and Harrison (1998) scheme (for the coarse particle range). The DMS-sea salt interactions in the model are described in detail in Thomas et al. (2010). The organic emissions from the oceans are not included in our study though Wingenter et al. (2004) hypothesized that an increase in non-methyl hydrocarbons may increase the local lifetimes of short lived gases such as DMS by competing for $\mathrm{OH}$. Our analysis mainly focuses on the Southern ocean region, where anthropogenic influence is minimal and during SH summer months when low level clouds are prevalent.

We evaluate the impact of changes in DMS emissions on cloud microphysical properties and radiative forcing using the following diagnostics.

DIAG1 $=[($ CTRL - wo_ODMS $) /$ wo_ODMS $] \times 100 \%$

DIAG2 $=\left[\left(2 \mathrm{X} \_O D M S-\right.\right.$ wo_ODMS $) /$ wo_ODMS $] \times 100 \%$

DIAG3 $=\left[\left(2 \mathrm{X} \_\right.\right.$ODMS $\left.\left.-\mathrm{CTRL}\right) / \mathrm{CTRL}\right] \times 100 \%$

The diagnostics, DIAG1 and DIAG2 give the mean percentage change in the present day DMS emissions and in a doubled DMS scenario relative to a scenario with no DMS emissions. The comparison of DIAG1 and DIAG2 would give insight in to the non-linearity of the system. The DIAG3 measure is the mean percentage change in the aerosol parameters and cloud microphysics when the ocean DMS is doubled with respect to the present day DMS emissions.

\section{Results and discussion}

\subsection{Non-linearity in DMS-aerosol chemistry link}

The seasonal cycle and magnitude of the ocean DMS flux to the atmosphere in a doubled DMS sea water concentrations case and in the CTRL simulation averaged over the Southern oceans and globally is shown in Fig. 1. The seasonality in the fluxes follow that of the CTRL simulation, except that the magnitude is doubled. In the 2X_ODMS case, the mean DMS emissions in austral summer is about $8.17 \times 10^{-12} \mathrm{Kg}(\mathrm{S}) \mathrm{m}^{-2} \mathrm{~s}^{-1}$ when averaged over the $30^{\circ} \mathrm{S}-75^{\circ} \mathrm{S}$ latitudinal belt compared to a value of $4.08 \times 10^{-12} \mathrm{Kg}(\mathrm{S}) \mathrm{m}^{-2} \mathrm{~s}^{-1}$ in the CTRL simulation. The mean winter fluxes are respectively around $1.36 \times 10^{-12} \mathrm{Kg}(\mathrm{S}) \mathrm{m}^{-2} \mathrm{~s}^{-1}$ and $0.7 \times 10^{-12} \mathrm{Kg}(\mathrm{S}) \mathrm{m}^{-2} \mathrm{~s}^{-1}$ in 2X_ODMS simulation and CTRL simulations. Globally, the austral summer mean (annual mean) DMS flux to the atmosphere ranges from $1.95 \times 10^{-12} \mathrm{Kg}(\mathrm{S}) \mathrm{m}^{-2} \mathrm{~s}^{-1}$ $\left(1.45 \times 10^{-12} \mathrm{Kg}(\mathrm{S}) \mathrm{m}^{-2} \mathrm{~s}^{-1}\right)$ in the CTRL simulation to $3.91 \times 10^{-12} \mathrm{Kg}(\mathrm{S}) \mathrm{m}^{-2} \mathrm{~s}^{-1}\left(2.90 \times 10^{-12} \mathrm{Kg}(\mathrm{S}) \mathrm{m}^{-2} \mathrm{~s}^{-1}\right)$ in the 2X_ODMS simulation, indicating a linear response. However, the atmospheric DMS burden for the austral summer mean months averaged over the southern latitude belt is $0.034 \mathrm{Tg}(\mathrm{S})$ in the CTRL run (the global annual mean atmospheric DMS burden in CTRL is $0.050 \mathrm{Tg}(\mathrm{S}))$ and 0.106 $\mathrm{Tg}(\mathrm{S})$ in the 2X_ODMS run. The DMS burden is tripled when the ocean DMS emissions are doubled. This means that DMS is not converted to $\mathrm{SO}_{2}$ by $\mathrm{OH}$ oxidation in 2X_ODMS at same rate as in the CTRL. OH concentration is not sufficient to oxidize all the DMS when the emissions are doubled, so DMS accumulates, resulting in a three fold increase in the DMS burden.

The diagnostics for $\mathrm{SO}_{2}$ and $\mathrm{H}_{2} \mathrm{SO}_{4}$ column burdens, vertically integrated activated particle number concentration and AOD are presented in Table 1 during the mean austral summer months over $30^{\circ} \mathrm{S}-75^{\circ} \mathrm{S}$ mean latitude belt (The absolute numbers for the above mentioned parameters in wo_ODMS, CTRL and 2X_ODMS simulations are given in Table S1 in the Supplement.). Relative to the wo_ODMS emissions, both $\mathrm{SO}_{2}$ and $\mathrm{H}_{2} \mathrm{SO}_{4}$ burden increases by approximately $118 \%$ in the CTRL simulation. This points out to the efficient conversion of $\mathrm{SO}_{2}$ to $\mathrm{H}_{2} \mathrm{SO}_{4}$ or in other words, there is sufficient $\mathrm{OH}$ to facilitate the conversion of the $\mathrm{SO}_{2}$ to $\mathrm{H}_{2} \mathrm{SO}_{4}$. However, the percentage increase is $294.5 \%$ and $180.6 \%$ respectively for $\mathrm{SO}_{2}$ and $\mathrm{H}_{2} \mathrm{SO}_{4}$ column burdens in the 2X_ODMS simulation. A non-linear response is evident 
(a) averaged over $30 \mathrm{~S}-75 \mathrm{~S}$

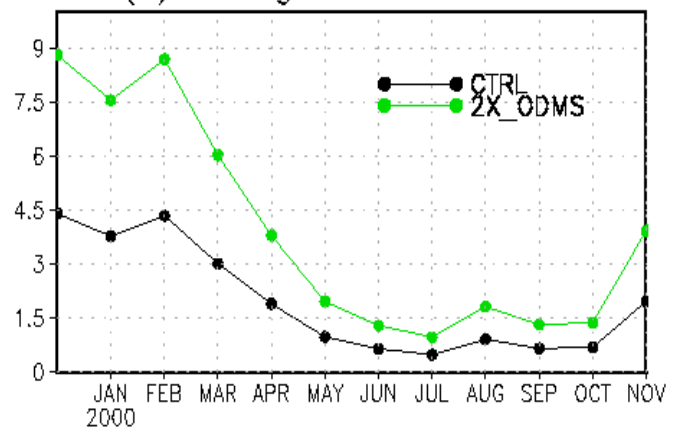

(b) averaged globally

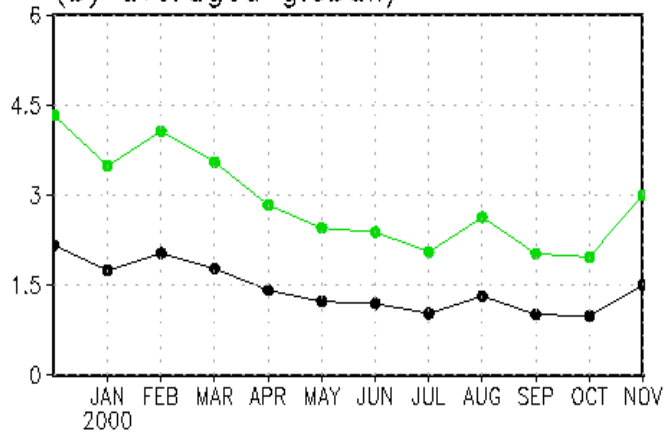

Fig. 1. Time series of ocean DMS emissions in $\mathrm{Kg}(\mathrm{S}) \mathrm{m}^{-2} \mathrm{~s}^{-1}$ in the $2 \mathrm{X}$ _ODMS (open circled line) and CTRL (plain line) simulations (a) averaged over $30^{\circ} \mathrm{S}-75^{\circ} \mathrm{S}$ and (b) averaged globally. The emissions are multiplied by $10^{12}$.

in both $\mathrm{SO}_{2}$ and $\mathrm{H}_{2} \mathrm{SO}_{4}$ burdens. In DIAG3, the increase in burdens of $\mathrm{SO}_{2}$ and $\mathrm{H}_{2} \mathrm{SO}_{4}$ concentrations are $80.9 \%$ and only $28.2 \%$ respectively in the 2X_ODMS simulation compared to the CTRL simulation. The relatively small percentage increase in all the diagnostics in the $\mathrm{H}_{2} \mathrm{SO}_{4}$ burden compared to the $\mathrm{SO}_{2}$ burden and the non-linearity can be explained as follows: the atmospheric DMS is converted to $\mathrm{SO}_{2}$ by the reactions with $\mathrm{OH}$ and $\mathrm{NO}_{3}$ (Pozzoli et al., 2008a; Stier et al., 2005; Feichter et al., 1996) which is further oxidized to $\mathrm{H}_{2} \mathrm{SO}_{4} . \mathrm{SO}_{2}$ is at the equilibrium between the gas- and aqueous- phases, the total dissolved $\mathrm{SO}_{2}$ depends on its partial pressure and the Henry's law constant, which increases by almost seven orders of magnitude as the $\mathrm{pH}$ increases from 1 to 8 . In the gas-phase, the reaction with the $\mathrm{OH}$ radical is dominant, produces sulfuric acid $\left(\mathrm{H}_{2} \mathrm{SO}_{4}\right)$, which rapidly gets converted to sulfate aerosol by nucleation and condensation. The $\mathrm{SO}_{2}$ dissolved in the aqueous-phase produces sulfate aerosol when oxidized by $\mathrm{O}_{3}$ and $\mathrm{H}_{2} \mathrm{O}_{2}$ ( $\mathrm{SO}_{2}$ in-cloud oxidation). In our simulations the sulfate production in the liquid phase is very much linear (not shown here) with doubling ocean DMS emissions. Also, the deposition (dry,wet and sedimentation) ratio, 2X_ODMS/CTRL is lower than 2. This means that there is a lower production of $\mathrm{SO}_{4}$ from gas phase oxidation. The higher percentage increase in $\mathrm{SO}_{2}$ concentrations compared to the $\mathrm{H}_{2} \mathrm{SO}_{4}$ is because of the lower $\mathrm{OH}$ oxidation taking place and hence, $\mathrm{SO}_{2}$ accumulates, thereby exhibiting a non-linear response in $\mathrm{SO}_{2}$ and $\mathrm{H}_{2} \mathrm{SO}_{4}$ burdens to the doubling of ocean DMS.

The vertically integrated number of activated particles over the southern oceans in austral summer increase by $116.7 \%$ in CTRL simulation and $179.2 \%$ in 2X_ODMS simulation relative to the wo_ODMS. It can be seen that the rate of increase is not doubled and does not scale up with the doubling of DMS emissions, hence the pathway is nonlinear. The number of activated particles is calculated based on the supersaturation and updraft velocity that depends nonlinearly on the total aerosol number and their size distribution and chemical composition. The number of activated particles
Table 1. Percentage mean (DJF mean) change in DIAG1, DIAG2 and DIAG3 for (a) $\mathrm{SO}_{2}$ column burden (b) $\mathrm{H}_{2} \mathrm{SO}_{4}$ column burden (c) vertically integrated number of activated particles (Num_act) and (d) aerosol optical depth (AOD) at $0.55 \mu \mathrm{m}$ averaged over $30^{\circ} \mathrm{S}-$ $75^{\circ} \mathrm{S}$.

\begin{tabular}{lcccc}
\hline Diagnostics & $\mathrm{SO}_{2}$ & $\mathrm{H}_{2} \mathrm{SO}_{4}$ & Num_act & AOD \\
\hline DIAG1 & 118.1 & 119.0 & 116.7 & 23.1 \\
DIAG2 & 294.5 & 180.6 & 179.2 & 50.3 \\
DIAG3 & 80.9 & 28.2 & 28.9 & 20.6 \\
\hline
\end{tabular}

increase by only $28.9 \%$ with the doubling of ocean DMS compared to the CTRL simulation. This is due to the saturation effect whereby enhanced aerosol concentrations diminish the supersaturation hindering activation of aerosol particles (Boucher and Lohmann, 1994).

In the model, AOD is obtained from a look up table of offline Mie calculations given the complex volume weighted mean refractive index of each aerosol mode taking into consideration all the aerosol components and aerosol water and the median radius. The resulting zonal mean DMS derived $\mathrm{AOD}$ at $0.55 \mu \mathrm{m}$ for the latitude belt $30^{\circ} \mathrm{S}-75^{\circ} \mathrm{S}$ is 0.1636 in the CTRL simulation and 0.2013 in the 2X_ODMS simulation for the SH summer months. The percentage increase in AOD in the 2X_ODMS simulation with respect to the CTRL simulation and also, for DIAG1 and DIAG2 diagnostics are presented in Table 1. The AOD is indirectly coupled to aerosol numbers and mass through size distribution, composition and mixing state. The percentage increases in AOD in DIAG1 and DIAG2 are $23.1 \%$ and $50.3 \%$. Relative to the no DMS emission scenario, the AOD is mostly doubled when the emissions in the CTRL simulation are doubled, indicating a linear behavior. However, DIAG3 shows that with a doubling of model ocean DMS, the model AOD increases by $20 \%$ over the $\mathrm{SH}$ summer months in the $30^{\circ} \mathrm{S}-75^{\circ} \mathrm{S}$ belt relative to the CTRL simulation. Here, a non-linear response is seen when the emissions are doubled in the CTRL scenario. 
Table 2. Percentage mean change in DIAG1, DIAG2, DIAG3 for zonally averaged CDNC burden over $30^{\circ} \mathrm{S}-75^{\circ} \mathrm{S}$ latitudinal belt.

\begin{tabular}{lcccc}
\hline Diagnostics & December & January & February & March \\
\hline DIAG1 & 103.9 & 112.9 & 114.2 & 83.0 \\
DIAG2 & 160.3 & 165.8 & 169.5 & 135.1 \\
DIAG3 & 27.7 & 24.9 & 25.8 & 28.5 \\
\hline
\end{tabular}

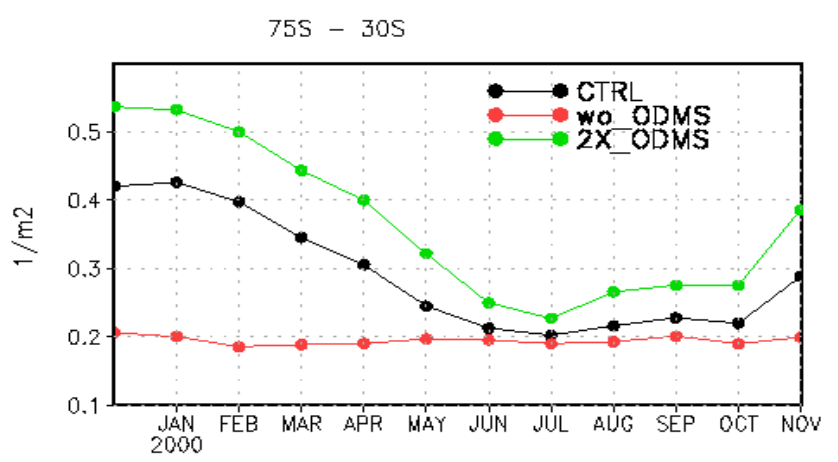

Fig. 2. Latitudinally averaged $\left(30^{\circ} \mathrm{S}-75^{\circ} \mathrm{S}\right)$ time series (December 1999-November 1999) of the vertically integrated CDNC $\left(1 \mathrm{~m}^{-2}\right)$ shown as absolute values in (a) CTRL simulation denoted by the black line (b) wo_ODMS simulation denoted by the red line and (c) 2X_ODMS simulation denoted by the green line. The variables are multiplied by $10^{-11}$.

The following subsections describe in detail the changes in the modeled cloud microphysical properties (such as CDNC burden, $\mathrm{CD}$ effective radii and cloud liquid water path) for a doubling of the ocean DMS flux. We also discuss the variation in the top of the atmosphere all sky radiative forcing. The changes are evaluated based on the diagnostics given in Sect. 2.

\subsection{Non-linearity in cloud microphysical link}

\subsubsection{CDNC burden}

The zonally averaged CDNC burden averaged over the Southern oceans $\left[30^{\circ} \mathrm{S}-75^{\circ} \mathrm{S}\right]$ is presented in Fig. 2 for the CTRL simulation (black line), wo_ODMS simulation (red line) and for the 2X_ODMS simulation (green line). An increase in CDNC burden in both CTRL and 2X_ODMS simulations compared to the wo_ODMS simulation is clearly evident. This increase is more pronounced in the austral summer months, associated with the intense biological activity during this period of the year and a minimum in the austral winter months. Also, it has to be noted that the CDNC burden increases with the doubling of the DMS emissions. Summarized in Table 2 for the SH summer months, averaged over the $30^{\circ} \mathrm{S}-75^{\circ} \mathrm{S}$ latitude belt, the CDNC burden is increased by $165 \%$ for the 2X_ODMS and $110 \%$ for the CTRL compared to the simulation with no DMS emissions
Table 3. Percentage mean change in DIAG1, DIAG2, DIAG3 for the zonally averaged $\mathrm{CD}$ effective radii over $30^{\circ} \mathrm{S}-75^{\circ} \mathrm{S}$ latitudinal belt.

\begin{tabular}{lcccc}
\hline Diagnostics & December & January & February & March \\
\hline DIAG1 & -6.32 & -5.96 & -6.04 & -5.36 \\
DIAG2 & --9.16 & -8.36 & -9.03 & -7.90 \\
DIAG3 & -3.04 & -2.56 & -3.18 & -2.68 \\
\hline
\end{tabular}

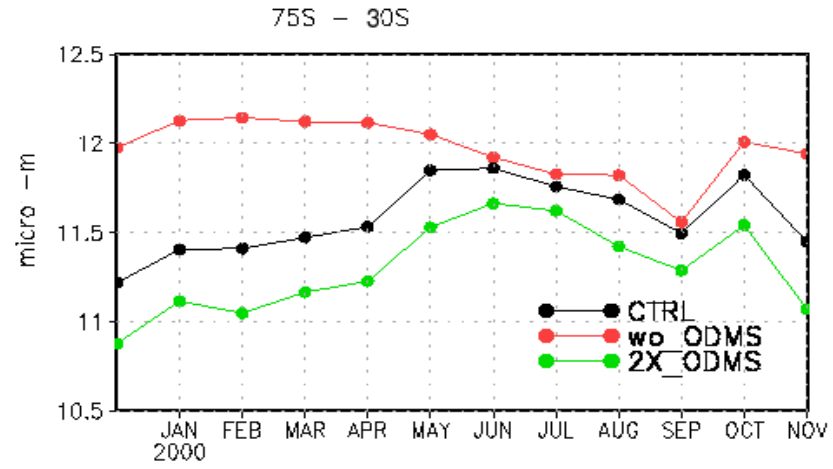

Fig. 3. Same as in Fig. 2, but, for, the cloud droplet effective radii $(\mu \mathrm{m})$.

(DIAG1 and DIAG2 respectively). This indicates that the processes governing the CDNC formation are non-linear, as the CDNC burden does not scale with the DMS emissions. The vertically integrated atmospheric liquid water remains constant in all these simulations which is one of the reasons why while the DMS emissions increase two fold, the droplet number concentrations increase by only $25 \%$ over the $30^{\circ} \mathrm{S}-$ $75^{\circ} \mathrm{S}$ latitude belt during $\mathrm{SH}$ summer (refer DIAG3 in Table 2) due to the saturation effect explained in the previous section and is in sync with the change in the number of activated particles. Boucher and Lohmann (1994) used an empirical relationship in their indirect effect parameterization between CDNC and sulfate mass and showed that an increase in CDNC with increasing aerosol load can take place only in relatively clean air. Globally, the CDNC burden increases by only $13.2 \%(13.1 \%)$ when the DMS emissions are doubled when averaged over DJF months (averaged annually).

\subsubsection{CD effective radii}

In Fig. 3 we present variations in the cloud top cloud droplet effective radii in the CTRL (black), wo_ODMS (red) and 2X_ODMS (green) simulations. The droplet size reaches a maximum of $12.2 \mu \mathrm{m}$ in the wo_ODMS case during the austral summer months. In both the CTRL and 2X_ODMS simulations, the droplet size is smaller (between $10.5 \mu \mathrm{m}$ and $11.5 \mu \mathrm{m})$ compared to the droplet size with no ocean DMS emissions. Also, it is evident that the droplet radius is even smaller when the DMS is doubled compared to the DMS 
in the CTRL simulation. The percentage differences of the simulated droplet radii presented in Table 3 in the CTRL (DIAG1) and 2X_ODMS (DIAG2) shows that the droplet radius is smaller by about $6 \%$ and $9 \%$ respectively compared to the droplet size in the wo_ODMS simulation when averaged over $30^{\circ} \mathrm{S}-75^{\circ} \mathrm{S}$ latitude belt in DJF, a clear signature of the first indirect aerosol effect. The cloud droplet radius is primarily determined by liquid water content in the cloud and CDNC, which depends on the number of aerosol particles. There are more activated particles in the 2X_ODMS simulation competing for the same amount of available atmospheric water (with only $0.11 \%$ increase in $2 X_{-}$ODMS compared to CTRL), thereby, resulting in a reduction in the droplet size. Here, we can see that the decrease in droplet size with a two fold increment in DMS emissions is non-linear. The DIAG3 gives the variation in the droplet radii in the 2X_ODMS compared to the DMS emissions in the CTRL simulation. The mean decrease is $2.9 \%$ when the DMS emissions are doubled.

\subsubsection{Cloud liquid water path}

The second IAE or the cloud lifetime effect is manifested as an increase in cloud liquid water path and hence, cloud cover. A decrease in cloud droplet effective radius due to an increase in aerosol amount leads to the decreased coalescence efficiency of cloud droplets. This further results in precipitation suppression and increase in cloud lifetime. The vertically integrated cloud liquid water in the three simulations carried out here are presented in Fig. 4. Here, it can be seen that there is an increase in cloud liquid water path when ocean DMS is included (black and green lines) in the simulations compared to the no DMS case (red line). This is because, the rate at which cloud droplets form rain drops is inversely proportional to CDNC, which means that an increase in aerosol concentrations and hence, CDNC delays the precipitation rate leading to increased liquid water path (Lohmann and Feichter, 1997). The seasonality observed in the CTRL and the 2X_ODMS simulations also follows the ocean DMS cycle with a maximum over the austral summer months and a minimum over the austral winter months. The cloud liquid water path increases with the doubling of ocean DMS over the $30^{\circ} \mathrm{S}-75^{\circ} \mathrm{S}$ latitude belt when compared to the CTRL scenario run.

Table 4 gives the percentage changes in the vertically integrated cloud liquid water over the Southern oceans in $\mathrm{SH}$ summer. An increase of approximately $44 \%$ in the CTRL and $61 \%$ in the 2X_ODMS simulation with respect to the wo_ODMS simulation is simulated over the SH summer months when averaged south of 30S. Maximum increase in the cloud liquid water path is seen in the northern most band in the $30^{\circ} \mathrm{S}-75^{\circ} \mathrm{S}$ latitude band, with an average increase of $11.7 \%$ over the Southern oceans, when the DMS emissions are doubled with respect to the DMS emissions in the CTRL simulation. Globally, an annual mean increase of $7.5 \%$ is es-
Table 4. Percentage mean change in DIAG1, DIAG2, DIAG3 for the zonally and vertically averaged cloud liquid water over $30^{\circ} \mathrm{S}-$ $75^{\circ} \mathrm{S}$ latitudinal belt.

\begin{tabular}{lcccc}
\hline Diagnostics & December & January & February & March \\
\hline DIAG1 & 39.8 & 43.8 & 47.7 & 42.53 \\
DIAG2 & 56.8 & 59.7 & 65.3 & 60.1 \\
DIAG3 & 12.2 & 11.1 & 11.9 & 12.3 \\
\hline
\end{tabular}

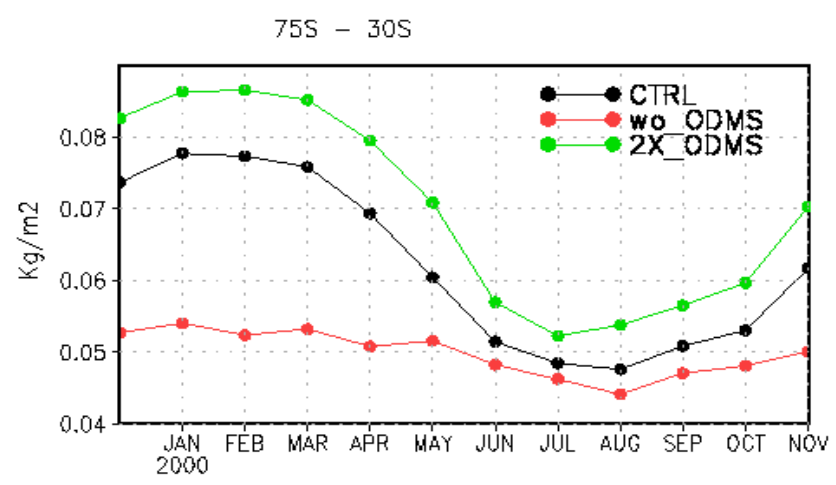

Fig. 4. Same as Fig. 2, but, for, the cloud liquid water path $\left(\mathrm{kg} \mathrm{m}^{-2}\right)$.

timated when the DMS emissions are doubled compared to the CTRL simulation which corresponds to a $0.35 \%$ increase in the total cloud cover (not shown).

\subsection{Aerosol radiative forcing at the TOA}

The TOA all sky radiative forcing is evaluated as the difference between the perturbed (CTRL and 2X_ODMS simulations) and the unperturbed (wo_ODMS) radiative fluxes (Thomas et al., 2010). The global annual mean DMS induced aerosol radiative forcing at the TOA is estimated as $-2.03 \mathrm{~W} \mathrm{~m}^{-2}$ in the CTRL simulation and $-3.42 \mathrm{~W} \mathrm{~m}^{-2}$ in the doubling DMS simulation. This means that under near constant atmospheric water vapor, a doubling of the DMS emissions can result in an additional cooling of $-1.4 \mathrm{~W} \mathrm{~m}^{-2}$ compared to the ocean DMS emissions in the CTRL simulation. Note that the current net global anthropogenic radiative forcing is $\sim 1.6 \mathrm{~W} \mathrm{~m}^{-2}$ compared to pre-industrial values (Solomon et al., 2007).

The TOA radiative forcing over the Southern oceans during the SH austral months are presented in Table 5 in the CTRL (given in brackets) and in the 2X_ODMS simulations. The values have a maximum of $-24 \mathrm{~W} \mathrm{~m}^{-2}$ and a minimum of $-6 \mathrm{~W} \mathrm{~m}^{-2}$ over the Southern oceans during SH summer for the 2X_ODMS case. In the CTRL scenario case, the radiative forcing at the TOA range between $-14 \mathrm{~W} \mathrm{~m}^{-2}$ and $-5 \mathrm{~W} \mathrm{~m}^{-2}$. The largest changes $\left(5 \mathrm{~W} \mathrm{~m}^{-2}\right)$ in the TOA radiative forcing for the 2X_ODMS case in comparison to the $\mathrm{CTRL}$ occur in the $30^{\circ} \mathrm{S}-60^{\circ} \mathrm{S}$ latitude band. However, 
Table 5. Top of the atmosphere, all sky radiative forcing in control DMS emission (given in brackets) and double DMS emissions case over the latitudinal belts as given in the table during the $\mathrm{SH}$ summer months.

\begin{tabular}{ccccc}
\hline Diagnostics & December & January & February & March \\
\hline $45^{\circ} \mathrm{S}-30^{\circ} \mathrm{S}$ & -19.02 & -18.69 & -19.21 & -14.77 \\
& $(-13.24)$ & $(-13.98)$ & $(-14.07)$ & $(-10.65)$ \\
$60^{\circ} \mathrm{S}-45^{\circ} \mathrm{S}$ & -24.83 & -24.85 & -18.33 & -9.90 \\
& $(-17.67)$ & $(-18.57)$ & $(-13.86)$ & $(-6.98)$ \\
$75^{\circ} \mathrm{S}-60^{\circ} \mathrm{S}$ & -9.21 & -9.96 & -6.13 & -2.32 \\
& $(-7.67)$ & $(-7.71)$ & $(-5.06)$ & $(-1.71)$ \\
\hline
\end{tabular}

the variation in the TOA radiative forcing pertaining to a doubling of DMS is relatively small (maximum decrease is $-2.3 \mathrm{~W} \mathrm{~m}^{-2}$ ) in the Southern most belt in the SH.

\section{Summary and conclusions}

An assessment of the degree of non-linearity in DMS-cloudclimate interactions is crucial as it has implications for our understanding of these links in future climate as well as evaluation of geoengineering studies that propose to modulate low-level marine water clouds. The global model ECHAM5HAMMOZ enables us to investigate such non-linearity in different processes by taking into account the linked chemistry, aerosol and cloud microphysical processes. For this, we compared the DMS derived changes in the cloud microphysical properties between a control simulation and one in which DMS emissions were doubled. Simulations are carried out in the T42L31 resolution by forcing the model with ERA-40 meteorological fields for 13 months from Dec 1999. In these simulations the vertically integrated atmospheric water vapor is a constant. In the control simulation, the ocean DMS concentration is prescribed from the Kettle and Andreae (2000) database.

The main findings of this paper are summarized below. The DMS flux to the atmosphere is $8.34 \times 10^{-12} \mathrm{Kg}(\mathrm{S}) \mathrm{m}^{-2} \mathrm{~s}^{-1}$ in the CTRL simulation. With the doubling of the DMS emissions, we increase the $\mathrm{H}_{2} \mathrm{SO}_{4}$ burden by only $28 \%, \mathrm{SO}_{2}$ burden by $81 \%$ and AOD by $\sim 20 \%$ over the $\mathrm{SH}$ summer months in the $30^{\circ} \mathrm{S}-75^{\circ} \mathrm{S}$ belt. This resulted in an increase in the vertically integrated CDNCs by $25 \%$. Since the vertically integrated atmospheric liquid water vapor is a constant, an increase in CDNCs leads to a reduction in cloud droplet radius. We simulate a decrease by $3.4 \%$ in the droplet radius over the Southern oceans in DJF. The equivalent increase in cloud liquid water path is $10.7 \%$. These percentage deviations do not change substantially when averaged over the globe, as the largest changes in the DMS aerosol-cloud-climate interactions are observed over the Southern oceans which is a region of maximum DMS emissions during the $\mathrm{SH}$ summer. The aforementioned changes in cloud microphysical properties results in a global annual mean cooling at the TOA of $-3.42 \mathrm{~W} \mathrm{~m}^{-2}$; an additional cooling of $-1.4 \mathrm{~W} \mathrm{~m}^{-2}$ when the DMS emissions to the atmosphere are doubled. The results from our study implies that the aerosol chemistrycloud microphysics link is highly non-linear. Finally, we would like to mention that the discussions on geoengineering methodologies that propose modulations of low-level marine water clouds are centered mainly on two aerosol proposals: one where the injection of sea salt aerosols to counteract warming is envisaged, and the other, where iron fertilization in oceans is estimated to stimulate DMS-cloud climate interactions. The present study would provide useful insights in evaluating the latter proposal.

\section{Supplement related to this article is available online at: http://www.atmos-chem-phys.net/11/11175/2011/ acp-11-11175-2011-supplement.pdf.}

Acknowledgements. This work was supported and funded by the QUEST-feedbacks project under the UK Natural Environment Research Council (NERC) QUEST programme.

Edited by: M. Kulmala

\section{References}

Albrecht, B.: Aerosols, cloud microphysics and fractional cloudiness, Science, 245, 1227-1230, 1989.

Auvray, M., Bey, I., Llull, E., Schultz, M. G., and Rast, S.: A model investigation of tropospheric ozone chemical tendencies in long-range transported pollution plumes, J. Geophys. Res. 112, D05304, doi:10.1029/2006JD007137, 2007.

Boucher, O. and Lohmann, U.: The sulfate-CCN-cloud albedo effect, Tellus, 47B, 281-300, 1994.

Boucher, O., Moulin, C., Belviso, S., Aumont, O., Bopp, L., Cosme, E., von Kuhlmann, R., Lawrence, M. G., Pham, M., Reddy, M. S., Sciare2, J., and Venkataraman, C.: DMS atmospheric concentrations and sulphate aerosol indirect radiative forcing: a sensitivity study to the D MS source representation and oxidation, Atmos. Chem. Phys., 3, 49-65, doi:10.5194/acp-3-49-2003, 2003.

Boyd, P. W.: Ranking geo-engineering schemes, Nature Geosci., 1, 722-724, 2008.

Carslaw, K. S., Boucher, O., Spracklen, D. V., Mann, G. W., Rae, J. G. L., Woodward, S., and Kulmala, M.: A review of natural aerosol interactions and feedbacks within the Earth system, Atmos. Chem. Phys., 10, 1701-1737, doi:10.5194/acp-10-17012010, 2010.

Chuang, C. C. and Penner, J. E.: Effects of anthropogenic sulfate on cloud drop nucleation and optical properties, Tellus, 47B, 566577, 1995.

Feichter, J., Kjellstrom, E., Rodhe, H., Dentener, F., Lelieveld, J., and Roelofs, G.: Simulation of the tropospheric sulfur cycle in a global climate model, Atmos. Environ., 30, 1693-1707, 1996.

Gondwe, M., Krol, M., Gieskes, W., Klaassen, W., and de Baar, H.: The contribution of ocean-leaving DMS to the global atmo- 
spheric burdens of DMS, MSA, $\mathrm{SO}_{2}$, and $\mathrm{nssSO}_{4}=$, Global Biogeochem. Cy., 17, 1056, doi:10.1029/2002GB001937, 2003.

Jones, A., Haywood, J., and Boucher, O.: Climate impacts of geoengineering marine stratocumulus clouds, J. Geophys. Res., 114, D10106, doi:10.1029/2008JD011450, 2009.

Kettle, A. and Andreae, M.: Flux of dimethylsulfide from the oceans: A comparison of updated data sets and flux models, J. Geophys. Res., 105, 26793-26808, 2000.

Khairoutdinov, M. and Kogan, Y.: A new cloud physics parameterization in a large-eddy simulation model of marine stratocumulus, Mon. Weather Rev., 128, 229-243, 2000.

Korhonen, H., Carslaw, K. S., and Romakkaniemi, S.: Enhancement of marine cloud albedo via controlled sea spray injections: a global model study of the influence of emission rates, microphysics and transport, Atmos. Chem. Phys., 10, 4133-4143, doi:10.5194/acp-10-4133-2010, 2010.

Latham, J., Rasch, P., Chen, C.-C., Kettles, L., Gadian, A., Gettelman, A., Morrison, H., Bower, K., and Choularton, T.: Global temperature stabilization via controlled albedo enhancement of low-level maritime clouds, Philos. T. R. Soc. A, 366, 3969-3987, 2008.

Lohmann, U. and Feichter, J.: Impact of sulfate aerosols on albedo and lifetime of clouds: A sensitivity study with the ECHAM4 GCM, J. Geophys. Res., 102, 13685-13700, 1997.

Lohmann, U. and Feichter, J.: Global indirect aerosol effects: a review, Atmos. Chem. Phys., 5, 715-737, doi:10.5194/acp-5-7152005, 2005.

Lohmann, U., Feichter, J., Chuang, C. C., and Penner, J. E.: Predicting the number of cloud droplets in the ECHAM GCM, J. Geophys. Res., 104, 9169-9198, 1999.

Lohmann, U., Stier, P., Hoose, C., Ferrachat, S., Kloster, S., Roeckner, E., and Zhang, J.: Cloud microphysics and aerosol indirect effects in the global climate model ECHAM5-HAM, Atmos. Chem. Phys., 7, 3425-3446, doi:10.5194/acp-7-3425-2007, 2007.

Monahan, E., Spiel, D., and Davidson, K.: Oceanic whitecaps and their role in air-sea exchange, chapter: A model of marine aerosols generation via whitecaps and wave disruption, D. Reidel, Norwell, Massachusetts, USA, 252 ed., 167-174, 1986.

Nightingale, P. D., Malin, G., Law, C. S., Liss, A. J. W. P. S., Liddicoat, M. I., Boutin, J., and Upstill-Goddard, R. C.: In situ evaluation of air-sea gas exchange parameterizations using novel conservative and volatile tracers, Global Biogeochem. Cy., 14, 373 388,2000

Pandis, S. N., Russell, L. M., and Seinfeld, J. H.: The relationship between DMS flux and CCN concentrations in remote marine regions, J. Geophys. Res., 99, 16945-16957, 1994.

Peng, Y. and Lohmann, U.: Sensitivity study of the spectral dispersion of the cloud droplet size distribution on the indirect aerosol effect, Geophys. Res. Lett, 30, 1507, doi:10.1029/2003GL017192, 2003.

Pozzoli, L.: Climate and chemistry interactions: Development and evaluation of a coupled chemistry-aerosol-climate model, $\mathrm{PhD}$ thesis, Ecole Polytech. Fed. de Lausanne, Lausanne, Switzerland, 2007.

Pozzoli, L., Bey, I., Rast, J. S., Schultz, M. G., Stier, P., and Feichter, J.: Trace gas and aerosol interactions in the fully coupled model of aerosol-chemistry-climate ECHAM5HAMMOZ: 1. Model description and insights from the spring
2001 TRACE-P experiment, J. Geophys. Res., 113, D07308, doi:10.1029/2007JD009007, 2008a.

Pozzoli, L., Bey, I., Rast, J. S., Schultz, M. G., Stier, P., and Feichter, J.: Trace gas and aerosol interactions in the fully coupled model of aerosol-chemistry-climate ECHAM5HAMMOZ: 2. Impact of heterogeneous chemistry on the global aerosol distributions, J. Geophys. Res., 113, D07309, doi:10.1029/2007JD009008, 2008b.

Quaas, J., Ming, Y., Menon, S., Takemura, T., Wang, M., Penner, J. E., Gettelman, A., Lohmann, U., Bellouin, N., Boucher, O., Sayer, A. M., Thomas, G. E., McComiskey, A., Feingold, G., Hoose, C., Kristjánsson, J. E., Liu, X., Balkanski, Y., Donner, L. J., Ginoux, P. A., Stier, P., Grandey, B., Feichter, J., Sednev, I., Bauer, S. E., Koch, D., Grainger, R. G., Kirkevg, A., Iversen, T., Seland, Ø., Easter, R., Ghan, S. J., Rasch, P. J., Morrison, H., Lamarque, J.-F., Iacono, M. J., Kinne, S., and Schulz, M.: Aerosol indirect effects -general circulation model intercomparison and evaluation with satellite data, Atmos. Chem. Phys., 9, 8697-8717, doi:10.5194/acp-9-8697-2009, 2009.

Rasch, P. J., Latham, J., and Chen, C. C.: Geoengineering by cloud seeding: Influence on sea ice and climate system., Environ. Res. Lett., 4, 8 pp., 2009.

Rast, S., Schultz, M. G., Aghedo, A. M., Bey, I., Brasseur, G. P., Diehl, T., Esch, M., Ganzeveld, L., Kirchner, I., Kornblueh, L., Rhodin, A., Roeckner, E., Schmidt, H., Schroeder, S., Schulzweida, U., Stier, P., and van Noije, T.: Evaluation of the tropospheric chemistry general circulation model ECHAM5$\mathrm{MOZ}$ and its application to the analysis of the interannual variability in tropospheric ozone from 1960-2000, chemical composition of the trosposphere for the period 1960-2000 (RETRO), MPI-Reports on Earth System Science, in preparation, 2011.

Russell, L. M., Pandis, S. N., and Seinfeld, J. H.: Aerosol production and growth in the marine boundary layer, J. Geophys. Res. 99, 20989-21003, 1994.

Salter, S., Sortino, G., and Latham, J.: Sea-going hardware for the cloud albedo method of reversing global warming., Phil. Trans.R. Soc., A366, 3989-4006, 2008.

Smith, M. and Harrison, N.: The sea spray generation function, J. Aerosol Sci., 29, 189-190, 1998.

Solomon, S., Qin, D., Manning, M., Chen, Z., Marquis, M., Averyt, K., Tignor, M., and Miller, H. L. (eds.): IPCC, 2007: Summary for Policymakers, in: Climate Change 2007: The Physical Science Basis. Contribution of Working Group I to the Fourth Assessment Report of the Intergovernmental Panel on Climate Change., Cambridge University Press, Cambridge, UK and New York, NY, USA, 2007.

Stier, P., Feichter, J., Kinne, S., Kloster, S., Vignati, E., Wilson, J., Ganzeveld, T., Tegen, I., Werner, M., Balkanski, Y., Schulz, M., Boucher, O., Minikin, A., and Petzold, A.: The aerosolclimate model ECHAM5-HAM, Atmos. Chem. Phys., 5, 11251165, doi:10.5194/acp-5-1125-2005, 2005.

Thomas, M. A., Suntharalingam, P., Pozzoli, L., Rast, S., Devasthale, A., Kloster, S., Feichter, J., and Lenton, T. M.: Quantification of DMS aerosol-cloud-climate interactions using the ECHAM5-HAMMOZ model in a current climate scenario, Atmos. Chem. Phys., 10, 7425-7438, doi:10.5194/acp-10-74252010, 2010.

Tompkins, A. M.: A prognostic parameterization for the subgridscale variability of water vapor and clouds in large-scale models 
and its use to diagnose cloud cover, J. Atmos. Sci., 59, 19171942, 2002.

Twomey, S. A.: Pollution and the Planetary Albedo, Atmos. Environ., 8, 1251-1256, 1974

Twomey, S. A.: The influence of pollution on the shortwave albedo of clouds, J. Atmos. Sci., 34, 1149-1152, 1977.

Wingenter, O. W., Haase, K. B., Strutton, P., Friederich, G., Meinardi, S., Blake, D. R., and Roland, F. S.: Changing concentrations of $\mathrm{CO}, \mathrm{CH}_{4}, \mathrm{C}_{5} \mathrm{H}_{8}, \mathrm{CH}_{3} \mathrm{Br}, \mathrm{CH}_{3} \mathrm{I}$, and dimethyl sulfide during the Southern Ocean Iron Enrichment Experiments, Proc. Natl. Acad. Sci., 101, 8537-8541, 2004.
Wingenter, O. W., Elliot, S. M., and Blake, D. R.: New directions: Enhancing the natural sulphur cycle to slow global warming, Atmos. Environ., 41, 7373-7375, 2007.

Woodhouse, M. T., Mann, G. W., and Carslaw, K. S.: New Directions: The impact of oceanic iron fertilization on cloud condensation nuclei, Atmos. Environ., 42, 5728-5730, 2008. 